\title{
Nonlocal Buckling Analysis of Single-Walled Carbon Nanotube Using Differential Transform Method (DTM)
}

\author{
Ravi Kumar ${ }^{1}$, Sumit Deol ${ }^{2}$ \\ ${ }^{1}$ Assistant Professor of School of Mechanical Engineering, SASTRA University, Thanjavur, India \\ ${ }^{2}$ P.G. student of School of Mechanical Engineering, SASTRA University, India
}

\begin{abstract}
In this work Differential Transform Method (DTM) is used to study the buckling behavior of the single walled carbon nanotube (SWCNT). The critical buckling load is being found out up to fourth degree accuracy for different boundary conditions, i.e. Clamped-Clamped, Simply Supported at ends, Clamped Hinged, and Clamped Free. Effect of different nonlocal parameters, different $L / d$ ratio on critical buckling load is being discussed. The DTM is implemented for the nonlocal SWCNT analysis and this yields results with high degree of accuracy. Further, present method can be applied to linear and nonlinear problems.
\end{abstract}

Keywords: Buckling, DTM, nonlocal, SWCNT, L/d ratio

\section{Introduction}

Carbon nanotubes (CNTs) are allotropes of carbon with a cylindrical nanostructure. Nanotubes have been constructed with length-to-diameter ratio of up to $132,000,000: 1$ [33] significantly larger than any other material. These cylindrical carbon molecules have novel properties[1],[4], and [5], making them potentially useful in many applications in nanotechnology, aerospace, electronics, optics, and other fields of materials science, as well as potential uses in architectural fields. The structure of an SWNT can be conceptualized by wrapping a one-atom-thick layer of graphite called graphene into a seamless cylinder[1] and[6]. Single-walled nanotubes are an important variety of carbon nanotube because they exhibit electric properties that are not shared by the multi-walled carbon nanotube (MWNT) variants [4]. Single-walled nanotubes are the most likely candidate for miniaturizing electronics beyond the microelectromechanical scale currently used in electronics [9]. The most basic building block of these systems is the electric wire, and SWNTs can be excellent conductors. Carbon nanotubes are the strongest and stiffest materials yet discovered in terms of tensile strength and Elastic Modulus respectively [2],[7], and [13]. This strength results from the covalent $\mathrm{sp}^{2}$ bonds formed between the individual carbon atoms. Since carbon nanotubes have a low density for a solid of 1.3 to $1.4 \mathrm{~g} \cdot \mathrm{cm}^{-3}$, its specific strength of up to 48,000 $\mathrm{KN} \cdot \mathrm{m} \cdot \mathrm{kg}^{-1}$ is the best of known materials, compared to high-carbon steel's $154 \mathrm{KN} \cdot \mathrm{m} \cdot \mathrm{kg}^{-1}$ [25], and [30].

Table 1: Comparison of mechanical properties [34]

\begin{tabular}{|c|c|c|c|}
\hline Material & $\begin{array}{c}\text { Young's } \\
\text { Modulus(TPa) }\end{array}$ & $\begin{array}{c}\text { Tensile } \\
\text { Strength } \\
\text { (GPa) }\end{array}$ & $\begin{array}{c}\text { Elongation at } \\
\text { break (\%) }\end{array}$ \\
\hline SWNT & $\sim 1$ (from 1 to 5) & $13-53$ & 16 \\
\hline Armchair SWNT & 0.94 & 126.2 & 23.1 \\
\hline Zigzag SWNT & 0.94 & 94.5 & $15.6-17.5$ \\
\hline Stainless Steel & $0.186-0.214$ & $0.38-1.55$ & $15-50$ \\
\hline
\end{tabular}

\section{Differential Transform Method}

The Differential Transform Method is a semi-analytical method based on the Taylor series expansion. In this method, certain transformation rules are applied and the governing differential equations and the boundary conditions of the system are transformed into a set of algebraic equations in terms of the differential transforms of the original functions. The solution of these algebraic equations gives the desired solution of the problem. The differential transformation of the kth derivative of function $\mathrm{u}(\mathrm{x})$ is defined as follows:

$$
U(k)=\frac{1}{k !}\left[\frac{d^{k} u(x)}{d x^{k}}\right]_{x=x_{0}}
$$

And the differential inverse transformation of $U(K)$ is expressed as

$$
u(x)=\sum_{k=0}^{\infty} U(k)\left(x-x_{0}\right)^{k}
$$

In real application function, $\mathrm{u}(\mathrm{x})$ is expressed as finite series and equation (2) can be written as:

$$
u(x)=\sum_{k=0}^{n} U(k)\left(x-x_{0}\right)^{k}
$$

Now using certain transformation rules we can convert the governing differential equation and associated Boundary Conditions into some algebraic equations and after solving them we can get the desired results. We can use the following transformation table for this purpose.

Table 2: Differential Transformations for Mathematical Equations

\begin{tabular}{|l|}
\hline Original Function Transformed Function \\
\hline$y(x)=u(x) \pm v(x) \quad Y(x)=U(k) \pm V(k)$ \\
\hline$y(x)=\lambda u(x) \quad Y(k)=\lambda U(k)$ \\
\hline$y(x)=\frac{d^{n} u(x)}{d x^{n}} \quad Y(k)=(k+1)(k+2) \ldots(k+n) U(k+n)$ \\
\hline
\end{tabular}




\section{International Journal of Science and Research (IJSR) \\ ISSN (Online): 2319-7064}

Index Copernicus Value (2013): 6.14 | Impact Factor (2014): 5.611

\section{Formulation}

\section{A. Non-Local Formulation of SWCNT}

In this study, we considered the Euler-Bernoulli beam model using stress gradient approach for the buckling analysis of SWCNT with nonlocal effect. The governing differential equation for the buckling [13] is

$$
E I \frac{d^{4} w}{d x^{4}}+P \frac{d^{2}}{d x^{2}}\left(w-\left(e_{0} a\right)^{2} \frac{d^{2} w}{d x^{4}}\right)=0
$$

Where $w=w(x, t)$ is the transverse beam deflection, $x, t$ are the spatial coordinate and the time; $\boldsymbol{E}$ is the Young modulus of elasticity; $\boldsymbol{P}$ is the buckling load, $\boldsymbol{I}$ is the moment of inertia of the beam cross-section, $\mathrm{e}_{0}$ is a constant appropriate to each material, a is an internal characteristic length. The parameter $\mathrm{e}_{0} \mathrm{a}$ is determined by matching the dispersion curves based on the atomic models [11].

\section{B. DTM Formulation}

In order to derive DTM form of Eq. (4), we refer Table 2 and the following expression can be written easily.

$(k+1)(k+2)(k+3)(k+4) W(k+4)=-r(k+1)(k+2)$

$$
\text { Where, } r=\frac{\left(P L^{2} / E I\right)}{\left[1-\left(e_{0} a\right)^{2}(P / E I)\right]}
$$

The analytical solution [14] for the Eq. (4) given by

$$
P_{\text {exact }}=\frac{(m \pi)^{2}\left(E I / L^{2}\right)}{\left(1+\left(e_{0} a\right)^{2}(m \pi / L)^{2}\right)} \text { (7) }
$$

Where $m=1$ for simply supported, $m=2$ for clampedclamped, and also $m=1 / 0.7$ for clamped-simply supported \& $m=1 / 2$ for cantilever column are considered for the first mode of buckling load.

\section{Application of Boundary Conditions}

1) Clamped at Both Ends

In this case, consider the column supported by clamped at both the ends and the boundary conditions defined as

$w(0)=0, w^{\prime}(0)=0, w(L)=0, w^{\prime}(L)=0(8)$

\section{2) Simply Supported at Both Ends}

The boundary conditions for the case of simply supported SWCNT at both the ends are defined as$$
w(0)=0, w^{\prime \prime}(0)=0, w(L)=0, w^{\prime \prime}(L)=0
$$

\section{3) Clamped at One End Hinged At Another}

For the SWCNT supported by clamped at one end and Hinged at the other end, the boundary conditions are defined as

$w(0)=0, w^{\prime}(0)=0, w(L)=0, w^{\prime \prime}(L)=0$

(10)

\section{4) Clamped at One End Free at Another}

For the SWCNT supported by clamped at one end and free at the other end, the boundary conditions are defined as

$$
\begin{aligned}
& w(0)=0, w^{\prime}(0)=0, M(L)=0, V(L)=0 \\
& M_{N L}=-E I\left(\frac{d^{2} w}{d x^{2}}+\left(e_{0} a\right)^{2} \frac{d^{4} w}{d x^{4}}\right) \\
& N_{N L}=-E I\left(\frac{d^{3} w}{d x^{3}}+\left(e_{0} a\right)^{2} \frac{d^{5} w}{d x^{5}}\right)-P \frac{d w}{d x}
\end{aligned}
$$

Here, $\boldsymbol{M}_{N L}$ and $\boldsymbol{V}_{N L}$ are the nonlocal moment and nonlocal shear force.

\section{Results}

\section{a) Validation}

Now for the better understanding of DTM, we will take an example of Euler-Bernoulli Beam Model and will try to find out the critical buckling load of it and will compare the results with the exact solution. Taking the diameter of nanotube as $1 \mathrm{~nm}$.

\section{1) Clamped-Clamped Column}

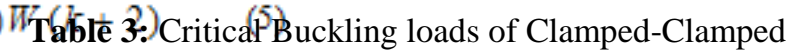
Column at both the ends

\begin{tabular}{|c|c|}
\hline Present & 39.478 \\
\hline Exact & 39.478 \\
\hline
\end{tabular}

\section{2) Simply Supported Column}

Table 4: Critical Buckling loads of Simply Supported Column at both the ends

\begin{tabular}{|c|c|}
\hline Present & 9.8696 \\
\hline Exact & 9.8696 \\
\hline
\end{tabular}

\section{3) clamped simply supported Column}

Table 5: Critical Buckling loads of column Clamped at one end and Hinged at another end

\begin{tabular}{|c|c|}
\hline Present & 20.142 \\
\hline Exact & 20.142 \\
\hline
\end{tabular}

\section{b) New Results}

\section{4) Comparison with Analytical Solutions}

The effective properties of SWCNT are taken as those of Reddy and Pang [35]. The Young's modulus $E=1000 \mathrm{GPa}$, mass density $\rho=2300 \mathrm{~kg} / \mathrm{m}^{3}$, Poisson's ratio $\nu=0.19$ are considered in the analysis.

The symbolic computer software package tool of MATLAB has been used to solve recurrence relations of critical buckling load with associated boundary conditions. By using the differential transform method as the numerical method the critical buckling load for SWCNT has been computed. After comparing with the analytical method, this proposed technique is very close to the exact results. Unlike the other approximated numerical methods, the DTM and the exact buckling loads are identical for the case of clampedclamped, simply supported and clamped free SWCNT. Here 


\section{International Journal of Science and Research (IJSR) \\ ISSN (Online): 2319-7064 \\ Index Copernicus Value (2013): 6.14 | Impact Factor (2014): 5.611}

the solution is obtained up to four decimal places. In the case of Clamped Hinged SWCNT, there is slight variation with the analytical method. It has been observed that the nonlocal parameter affected the buckling load and this effect has captured clearly by the DTM. When the nonlocal parameter is zero, the solution obtained for the classical EulerBernoulli beam model without nonlocal effect.

When d (diameter of carbon nanotube) $=1 \mathrm{~nm}$

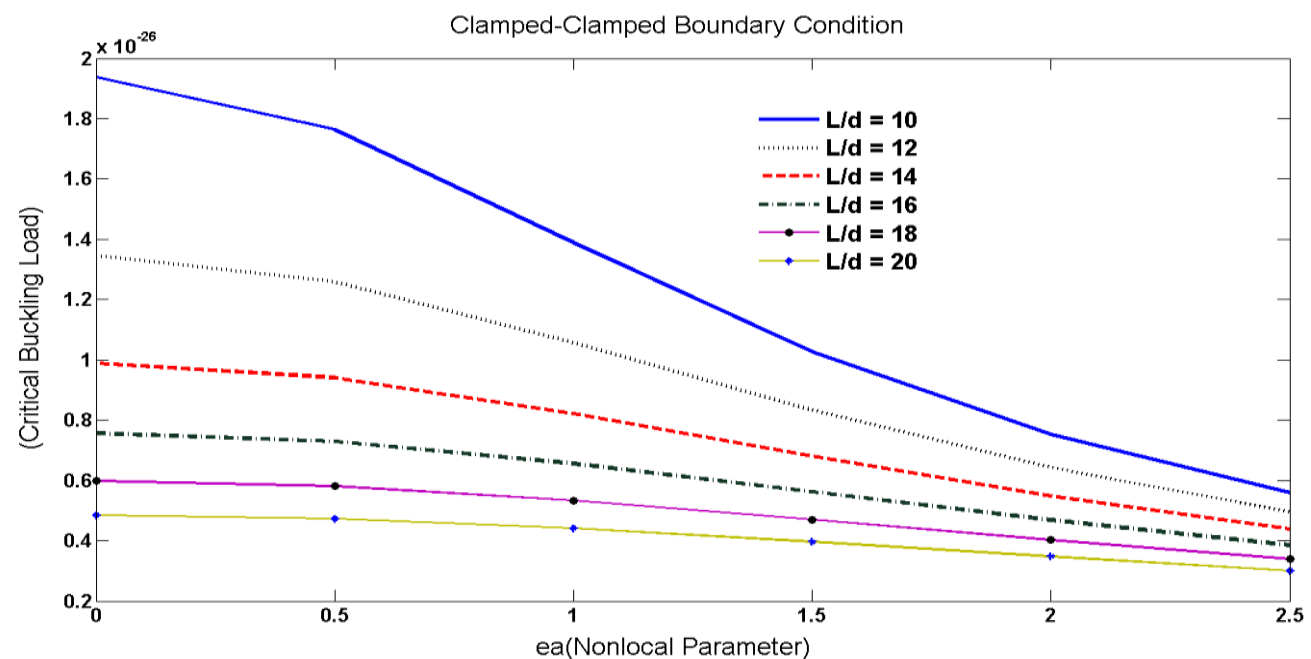

Figure 1: Critical buckling load (N) v/s non-local parameter for different L/d ratio for the Boundary Condition: Clamped at both ends

It is observed that critical buckling load is decreasing as nonlocal parameter increases, but for higher L/d ratio the rate of decrement decreases.

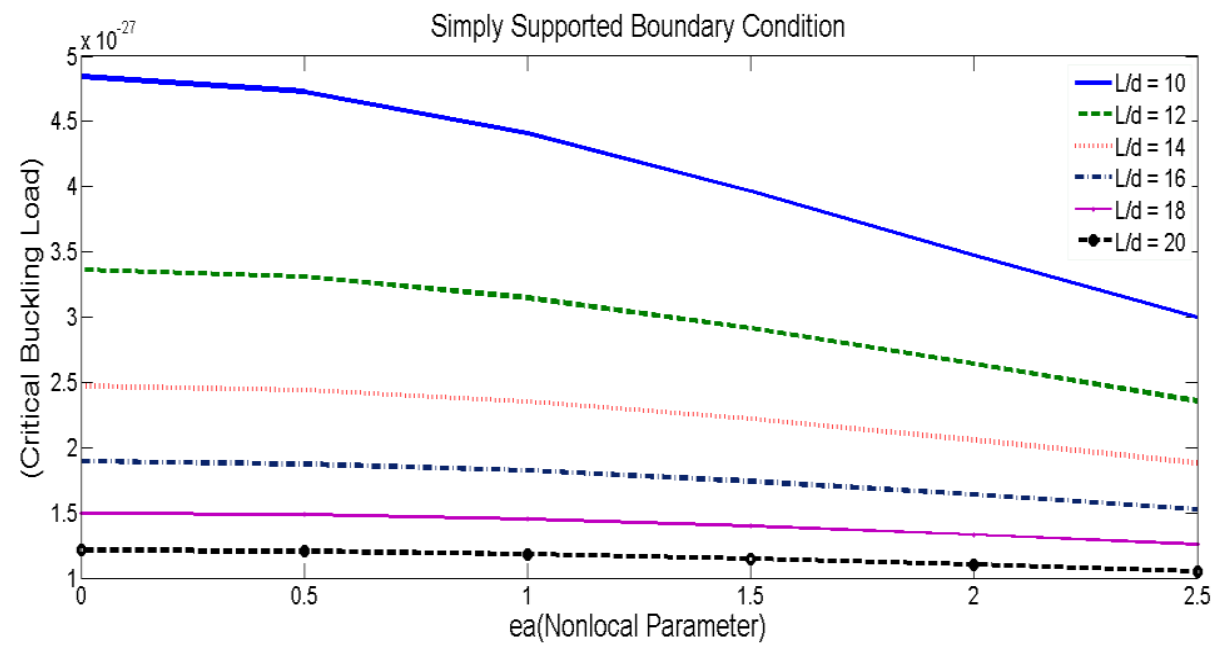

Figure 2: Critical buckling load (N) v/s non-local parameter for different L/d ratio

Boundary Condition: Simply supported at both ends

Again critical Buckling Load is decreasing as the nonlocal parameter increases but at higher L/d ratio the rate of decrement is very low 


\section{International Journal of Science and Research (IJSR) \\ ISSN (Online): 2319-7064}

Index Copernicus Value (2013): 6.14 | Impact Factor (2014): 5.611

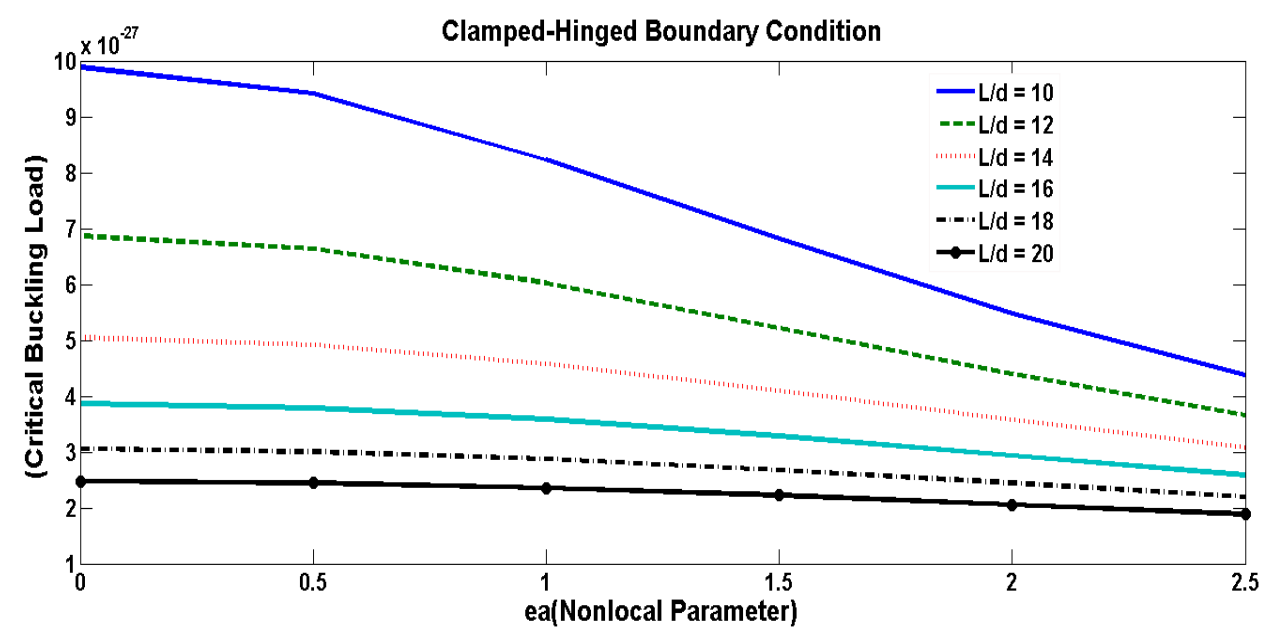

Figure 3: Critical buckling load (N)v/s non-local parameter for different $\mathrm{L} / \mathrm{d}$ ratio

Boundary Condition: Clamped at one end and hinged at another

Critical Buckling Load is decreasing as the nonlocal parameter increases but at higher L/d ratio the rate of decrement is very low.

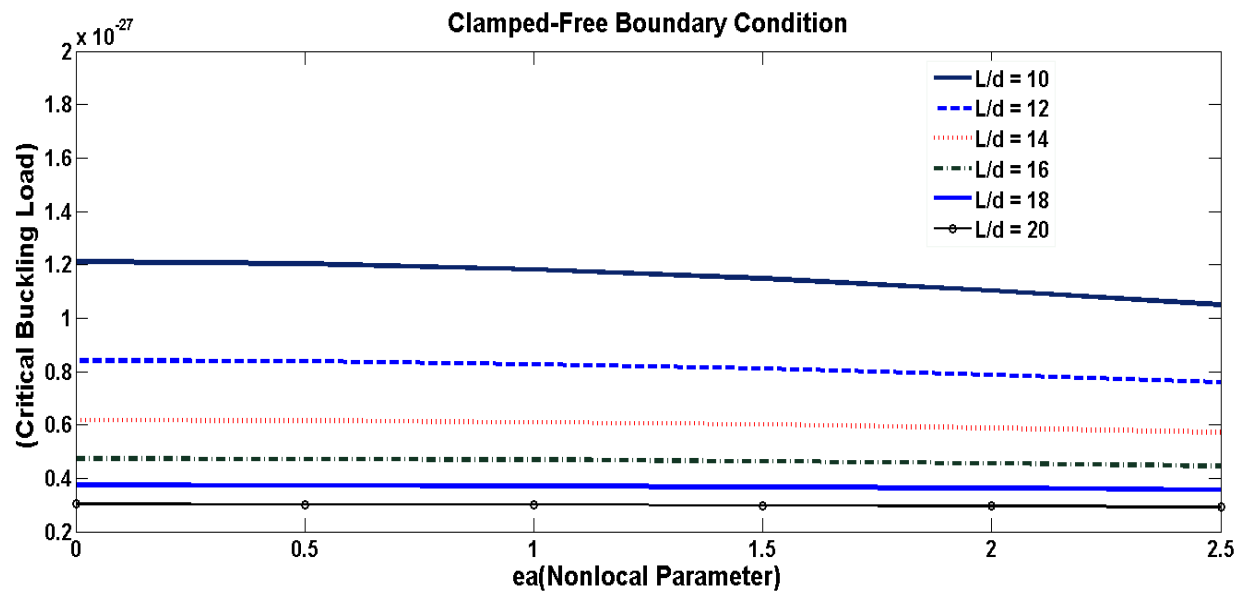

Figure 4: Critical buckling load (N) v/s non-local parameter for different $\mathrm{L} / \mathrm{d}$ ratio

Boundary Condition: Clamped at one end and free at another

Critical Buckling is decreasing with the increasing nonlocal parameter but the rate of decreasing is very low. So we can say that nonlocal parameter is not affecting the critical buckling load. Even at higher L/d, critical buckling load becomes almost constant.

\section{When $\mathrm{d}$ (diameter of carbon nanotube) $=2 \mathrm{~nm}$}

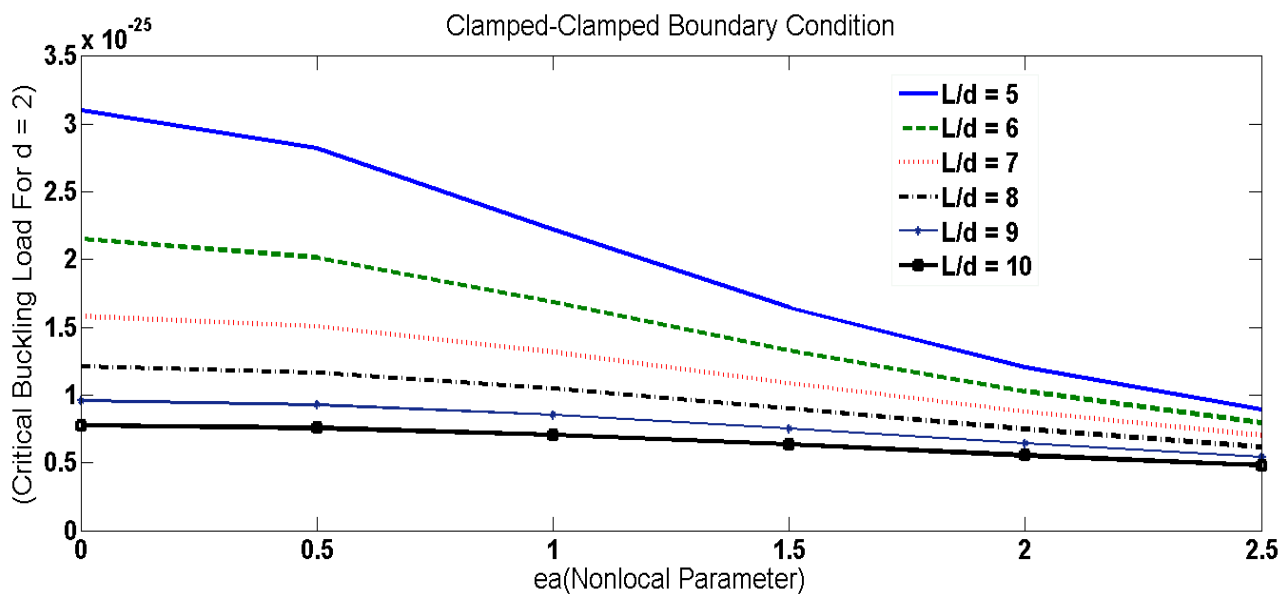

Figure 5: Critical buckling load (N) v/s non-local parameter for different $\mathrm{L} / \mathrm{d}$ ratio 


\section{International Journal of Science and Research (IJSR) \\ ISSN (Online): 2319-7064 \\ Index Copernicus Value (2013): 6.14 | Impact Factor (2014): 5.611}

Boundary Condition: Clamped at both ends

In this case also, the critical buckling load is decreasing with the higher nonlocal parameter. And at higher L/d ratio the buckling load almost remains constant. But when we increase the diameter we can clearly see that buckling load increases.

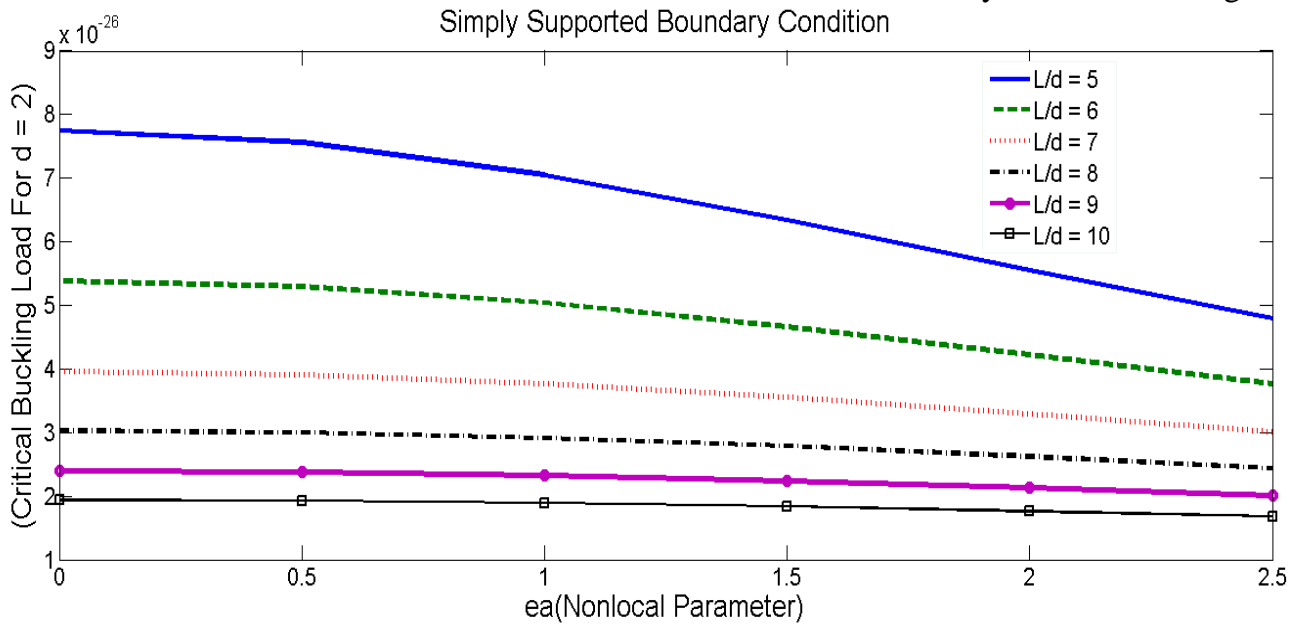

Figure 6: Critical buckling load (N) v/s non-local parameter for different L/d ratio

Boundary Condition: Simply Supported at both ends

In this case also, the critical buckling load is decreasing with the higher nonlocal parameter. And at higher L/d ratio the buckling load almost remains constant. But when we increase the diameter we can clearly see that buckling load increases.

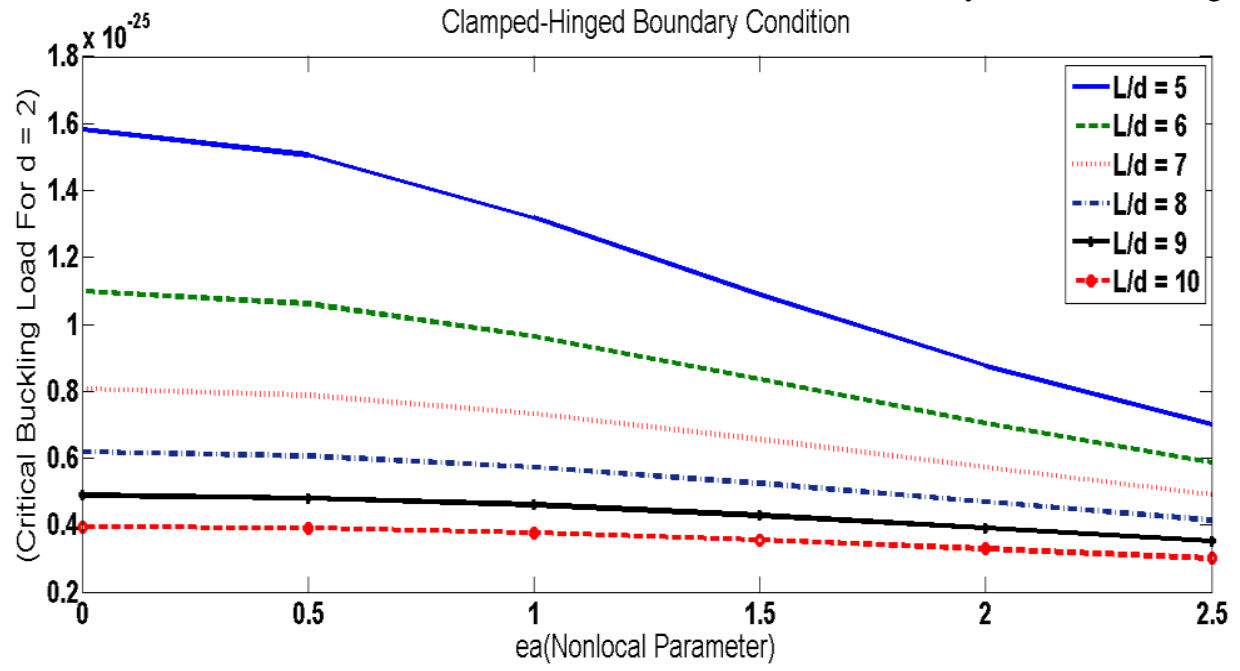

Figure 7: Critical buckling load (N) v/s non-local parameter for different L/d ratio

Boundary Condition: Clamped at one end and hinged at another

In this case also, the critical buckling load is decreasing with the higher nonlocal parameter. And at higher L/d ratio the buckling load almost remains constant. But when we increase the diameter we can clearly see that buckling load increases.

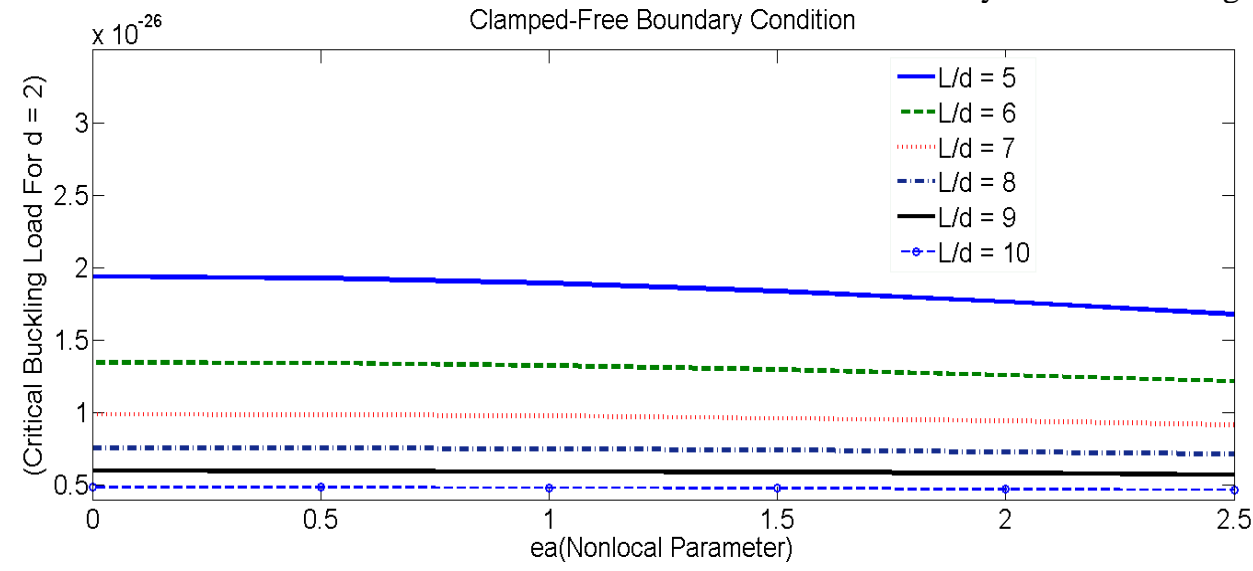

Figure 8: Critical buckling load (N) v/s non-local parameter for different L/d ratio 


\section{International Journal of Science and Research (IJSR) \\ ISSN (Online): 2319-7064 \\ Index Copernicus Value (2013): 6.14 | Impact Factor (2014): 5.611}

Boundary Condition: Clamped at one end free at another

In this case, we can clearly see that somehow for lower $\mathrm{L} / \mathrm{d}$ ratios critical buckling load decreases as nonlocal parameter increases but at higher $\mathrm{L} / \mathrm{d}$ ratio critical buckling load remains almost constant and as we increase the diameter critical buckling load decreases.

\section{Conclusion}

In this study, the buckling analysis of an SWCNT with a nonlocal theory for various boundary conditions like clamped-clamped, simply supported, clamped free and clamped hinged are studied by a semi-analytical numerical technique called the Differential Transform Method in a simple and accurate way. The simplicity of the solutions of the algebraic equations is remarkable because equations can be solved very quickly using the symbolic computational software, MATLAB. In this study, using DTM, the critical buckling loads have been calculated for various nonlocal parameter values. The calculated buckling load results are compared with analytical solutions and a very good close agreement is observed between the analytical and the present numerical method. From this analysis, it can be seen that the solutions obtained for a single-walled carbon nanotube can be helpful in investigating more complicated nanotube structures with nonlocal effects.

\section{References}

[1] S. Iijima, Nature 354 (1991) 58.

[2] E.K. Thostenson, Z. Ren, T.W. Chou, Compos. Sci. Technol. 61 (2001) 1899.

[3] D. Qian, G.J. Wagner, W.K. Liu, M.F. Yu, R.S. Ruoff, Appl. Mech. Rev. 55 (2002) 495.

[4] A.C. Eringen, J. Appl. Phys. 54 (1983) 4703.

[5] S.J. Zhou, Z.Q. Li, J. Shandong Univ. Technol. 31 (2001) 401.

[6] N.A. Fleck, J.W. Hutchinson, Adv. Appl. Mech. 33 (1997) 295.

[7] Yang, A.C.M. Chong, D.C.C. Lam, P. Tong, Int. J. Solids Struct. 39 (2002) 2731.

[8] L.J. Sudak, J. Appl. Phys. 94 (2003) 7281.

[9] Q. Wang, V.K. Varadhan, Smart Mater. Struct. 14 (2005) 281.

[10] B.I. Yakobson, C.J. Brabec, J. Bernholc, Phys. Rev. Lett. 76 (1996) 2511.

[11] A. Sears, R.C. Batra, Phys. Rev. B 73 (2006) 085410.

[12] J.N. Reddy, Int. J. Eng. Sci. 45 (2007) 288.

[13] S.C. Pradhan, T. Murmu, Physica E: Low-Dim. Syst. NanoStruct. 42 (2010) 1293.

[14]T. Murmu, S.C. Pradhan, Comput. Mater. Sci. 47 (2010) 721.

[15] T. Murmu, S.C. Pradhan, J. Appl. Phys. 106 (2009) 104301.

[16] T. Murmu, S.C. Pradhan, Mech. Res. Commun. 36 (2009) 933.

[17] S.C. Pradhan, T. Murmu, Comput. Mater. Sci. 47 (2009) 268.

[18] S.C. Pradhan, Phys. Lett. A 373 (2009) 4182.
[19] S.C. Pradhan, J.K. Phadikar, Struct. Eng. Mech. Int. J. 33 (2009) 193.

[20] S.C. Pradhan, A. Sarkar, Struct. Eng. Mech. Int. J. 32 (2009) 811.

[21] T. Murmu, S.C. Pradhan, Physica E: Low-Dim. Syst. NanoStruct. 41 (2009) 1628.

[22] S.C. Pradhan, T. Murmu, J. Appl. Phys. 105 (2009) 124306.

[23] S.C. Pradhan, J.K. Phadikar, G. Karthik, J. Inst. of Eng. (India), Met. Mater. Eng. Div. 90 (2009) 16.

[24] T. Murmu, S.C. Pradhan, Physica E: Low-Dim. Syst. NanoStruct. 41 (2009) 1232.

[25] S.C. Pradhan, J.K. Phadikar, Phys. Lett. A 373 (2009) 1062.

[26] T. Murmu, S.C. Pradhan, J. Appl. Phys. 105 (2009) 064319.

[27]J.K. Zhou, Differential Transformation and Its Applications for Electrical Circuits, Huazhong University Press, Wuhan, China, 1986.

[28] C.K. Chen, S.H. Ho, Appl. Math. Comput. 106 (1999) 171.

[29] A. Arıkog`lu, Appl. Math. Comput. 168 (2005) 1145.

[30] Q. Wang, V.K. Varadhan, S.T. Quek, Phys. Lett. A 357 (2006) 130.

[31] C.M. Wang, Y.Y. Zhang, S.S. Ramesh, S. Kitipornchai, J. Phys. D: Appl. Phys. 39 (2006) 3904.

[32] V. Senthilkumar, S.C. Pradhan, G. Pratap, Adv. Sci. Lett. 3 (2010) 1.

[33] Wang, X.; Li, Q.; Xie, J.; Jin, Z.; Wang, J.; Li, Y.; Jiang, K.; Fan, S. (2009). "Fabrication of Ultralong and Electrically Uniform Single-Walled Carbon Nanotubes on Clean Substrates". Nano Letters 9 (9): 3137-3141.

[34] Belluci, S. (19 January 2005). "Carbon nanotubes: physics and applications".: 34-47.

[35] J.N. Reddy, S.D. Pang J. Appl. Phys., 103 (2008), p. 023511. 